\title{
Catadoras(es) de materiais recicláveis e as possíveis articulações entre trabalho precário e relações de gênero
}

\author{
Izaque Machado Ribeiro ${ }^{1}$, \\ Henrique Caetano Nardi ${ }^{2}$ e Paula Sandrine Machado ${ }^{3}$ \\ Universidade Federal do Rio Grande do Sul (Porto Alegre, RS)
}

\begin{abstract}
Este artigo foi construído a partir de uma etnografia realizada com catadoras(es) de materiais recicláveis em uma cidade da região metropolitana de Porto Alegre. O objetivo foi pensar como a precarização das relações de trabalho atravessa as relações de gênero, questionando funções ditas e tidas culturalmente como masculinas e colocando as hierarquias de gênero em outra perspectiva. Tomaremos para análise dois espaços nos quais as(os) catadoras(es) se faziam presentes: as oficinas de formação e o trabalho no galpão de reciclagem. A partir disso, apontaremos quanto as relações de gênero, no que diz respeito aos tradicionais papéis masculinos e femininos, são modificadas de acordo com a necessidade que aquelas(es) trabalhadoras(es) têm em buscar seu sustento.
\end{abstract}

Palavras-chave: Catadoras(es) de materiais recicláveis, Relações de gênero, Trabalho precário.

Recycling workers and possible articulations between precarious work and gender relationships

This article describes an ethnography conducted with recycling workers in a city in Porto Alegre's metropolitan area. It aims at understanding how precarious labor relationships affect gender relationships, questioning tasks culturally assumed as masculine and seeing gender hierarchies through another perspective. We will analyze two workplaces frequented by recycling workers: training sessions and a recycling unit. In our analysis we will indicate how much traditional masculine and feminine roles are transformed in order to fulfill workers needs to earn enough to sustain themselves.

Keywords: Recycling workers, Gender relationships, Precarious work.

\section{Apresentação}

$E^{s}$

ste artigo discute uma pesquisa etnográfica realizada com catadoras(es) de uma cidade da região metropolitana de Porto Alegre, interrogando como se configuravam as relações de gênero e de trabalho frente a um contexto de trabalho marcado tradicionalmente pela precarização. Procuramos descrever os arranjos possíveis que demarcam o modo como os sujeitos catadores se constituem nesse contexto. Além disso, buscamos pensar de que forma são normatizados os corpos de quem trabalha com o que é "descartado" pela sociedade (Ribeiro, 2011).

O trabalho de campo teve duração de dez meses, entre setembro e julho de 2010. Nesse período, foi realizada observação participante nos locais de trabalho das(os) catadoras(es) (nos galpões de reciclagem e nas ruas) e nos espaços de formação para o trabalho e de reuniões das(os) trabalhadoras(es). O diário de campo $^{4}$, que constitui a principal

1 Mestre em psicologia social e institucional. Professor da Universidade Regional Integrada do Alto Uruguai e das Missões.

2 Professor do Programa de Pós-Graduação em Psicologia Social e Institucional da UFRGS. Coordenador do Núcleo de Pesquisas em Sexualidade e Relações de Gênero - NUPSEX.

3 Professora do Instituto de Psicologia e do Programa de Pós-Graduação em Antropologia Social da UFRGS. Pesquisadora do Núcleo de Pesquisas em Sexualidade e Relações de Gênero - NUPSEX.

4 O diário de campo é um instrumento de registro no qual se anotam diariamente os eventos da pesquisa e reflexões relativas ao que se observou e as interações estabelecidas no trabalho de campo. 
ferramenta do etnógrafo (Beaud \& Weber, 2007), foi utilizado como estratégia central de produção do corpus da pesquisa. Os sujeitos da pesquisa eram catadoras(es) de material reciclável, pertencentes ou não ao Movimento Nacional dos Catadores de Materiais Recicláveis (MNCR), sendo em sua maioria integrantes de uma cooperativa situada em uma cidade localizada na região metropolitana de Porto Alegre.

Neste artigo, a descrição densa, própria da pesquisa etnográfica, foi analisada a partir da perspectiva teórica dos estudos de gênero e de autores da sociologia do trabalho. Conforme Dagmar Meyer (2008), o conceito de gênero:

sinaliza não apenas para as mulheres e nem mesmo toma exclusivamente suas condições de vida como objeto de análise. Em vez disso, ele traz implícita a ideia de que as análises e as intervenções empreendidas devem considerar, ou tomar como referência, as relações de poder entre mulheres e homens - e as muitas formas sociais e culturais que os constituem como "sujeitos de gênero" (p. 18).

As relações de gênero inscrevem-se nos modos e processos de subjetivação, os quais, segundo Foucault (1988, p. 27), são "a maneira pela qual o indivíduo estabelece a relação com a regra e se reconhece como ligado à obrigação de pô-la em prática". Nesta direção, Judith Butler (2008) afirma que não há uma correspondência "natural" entre sexo, gênero, sexualidade e corpo na constituição dos sujeitos. Segundo a autora, "como fenômeno inconstante e contextual, o gênero não denota um ser substantivo, mas um ponto relativo de convergências entre conjuntos específicos de relações, cultural e historicamente convergentes" (p. 29).

A concepção pós-estruturalista de análise das relações de gênero e das sexualidades é importante para este trabalho, pois permite compreender o caráter de transitoriedade das identidades e das práticas, seja no campo das relações de gênero, seja em relação ao trabalho.

O texto está organizado em duas sessões: a primeira contextualiza sócio-historicamente o trabalho dos(as) catadores(as) de material reciclável, e a segunda descreve e analisa as relações de gênero no universo empírico estudado, enfocando sobretudo o galpão de triagem/reciclagem e os espaços de formação. Desta forma, a pesquisa buscou compreender como a precarização das relações de trabalho inflexiona as expressões de gênero, isto é, o modo como as relações de trabalho entre mulheres e homens, neste contexto, altera a organização e o processo de trabalho, uma vez que funções culturalmente atribuídas aos homens são assumidas por mulheres em situações específicas.

\section{Sobre as(os) catadoras(es)}

Como maneira de contextualização, podemos afirmar que as(os) catadoras(es) fazem parte de um grande contingente populacional que, devido às recentes transformações ocorridas no mundo do trabalho, em especial a partir da década de 1990, com a abertura dos mercados e a flexibilização das relações de trabalho, presencia a preponderância dos "ditames do livre mercado em detrimento das questões sociais" (Nardi, 2006, p. 54). De certo modo, fazendo uma alusão ao termo "supranumerários" de Castel (1998), as(os) catadoras(es) seriam aqueles(as) "que sobram" nesse modelo econômico vigente. As novas relações de trabalho estabelecidas pela reestruturação produtiva (passagem do modelo taylorista-fordista para o modelo de acumulação flexível) se caracterizam por empregos temporários, subcontratação e terceirização, e estas são algumas das diversas formas de precarização das relações de trabalho (Nardi, 2006) que estão, de forma muito marcante, presentes no trabalho de catadoras(es), como pretendemos mostrar neste artigo. 
De acordo com Freitas e Neves (2008), por volta de 1940, em Belo Horizonte, os(as) pedintes e catadores(as) já se faziam presentes na paisagem urbana. Dias (citado por Do Carmo, 2008), por sua vez, localiza os primórdios da atividade de catação no Brasil na década de 1930, quando era realizada por migrantes nordestinos também no contexto mineiro. Não existe de fato um consenso sobre o período em que se iniciaram as primeiras atividades de catadoras(es), no Brasil ou em outros países.

Segundo um dos catadores que participaram da presente pesquisa (ligado ao MNCR), na década de 1950, em São Paulo, já se notava a presença de pessoas que coletavam papelão e ossos nas ruas e em estabelecimentos comerciais. A esse respeito, Do Carmo (2008) indica que há muitas lacunas nos registros históricos sobre a atividade de catação. No entanto, há um consenso de que se trata de uma atividade tradicional, sendo considerada "a mais antiga atividade de recuperação do lixo em muitos países" (Do Carmo, 2008, p. 100).

No contexto argentino, Schamber (2006) classifica as(os) catadoras(es) em duas categorias: os estruturais (também chamados de "históricos") são aqueles que trabalham com catação há mais de cinquenta anos; os conjunturais - também chamados de recentes - são aqueles

que se integraram à catação na década de 1990, como consequência de uma permanente "queda" de atividades melhor pagas ou, ao menos, desenvolvidas em melhores condições laborais e, sem dúvida, muito menos estigmatizadas. Se trata, então, de uma incorporação fortemente relacionada à crise do emprego desse período (p. 91).

As denominações que estes(as) trabalhadores(as) recebem também são as mais diversas de acordo com o contexto em que estão inseridos. Conforme Do Carmo (2008),

de acordo com o local, aqueles que têm a cata do lixo como meio de subsistência recebem diferentes denominações: "packs and teugs" em Dacar, "wahis" e "zabbaleen" no Cairo, "gallinazos" na Colômbia, "chamberos" no Equador, "buzos" na Costa Rica, "cirujas" na Argentina, "catadores" no Brasil, "scavengers" ou "garbage pickers" em países de língua inglesa, "pepenadores" ou "resoqueadores" no México (p. 98).

Para a autora referida acima, haveria diversas formas de agrupar os catadores, conforme o critério a ser utilizado: local em que operam (catam), tipos de materiais que procuram, tipo de moradia em que residem e o tipo de relação que têm com os compradores.

Do Carmo (2008) define as(os) catadoras(es) como sujeitos que buscam seu sustento com o material reciclável produzido no meio urbano, e o tipo de material a ser reciclado varia conforme a demanda comercial de cada época. Para a autora, os locais de trabalho das(os) catadoras(es) são a rua (assim como em outras categorias de trabalhadores informais), coletando o material reciclável nos cestos de lixo; os galpões, participando do processamento do material reciclável; e suas casas, que muitas vezes servem de depósitos do material reciclável.

Quando se está nas ruas de uma grande cidade como Porto Alegre, por exemplo, vê-se o transitar de diversas pessoas que, de uma forma ou de outra, sobrevivem da atividade da catação. Um olhar mais atento verificará que existem alguns "tipos" de catadoras(es). Uns(umas) estarão com um saco plástico nas costas, utilizado para guardar o material que catam; outros(as) andarão com uma espécie de carrinho de supermercado pelas ruas, coletando o material reciclável; outros(as) utilizarão carroças e, mais raramente, veículos em mau estado, ou ainda veículos elétricos. É possível dizer, portanto, que o universo da catação é bastante heterogêneo no que diz respeito à forma como cada um exerce esse trabalho.

5 Alguns preferirão ser chamados de cartoneros, pois aquele outro termo remete à atividade de coleta do lixo, e não do material reciclável. Parece que ser chamado de cartonero tem a ver com a marcação de uma posição identitária e, também, parece uma tentativa de dissociar seu trabalho daquele que lida com o lixo, o qual teria um status negativo perante a sociedade (por mexer com suas sobras). 
O trabalho de catação é também heterogêneo no que se refere a sua finalidade. É possível encontrar pessoas que estão catando para suprir momentaneamente, com o pouco rendimento de um dia de trabalho, uma dependência química (álcool e outras drogas). Outras estarão buscando na catação uma renda extra, pois já trabalham em outra atividade. Algumas trabalharão sozinhas, por decisão própria, ou em associações ou cooperativas, por meio de acordos mais ou menos solidários com seus companheiros de trabalho. Haverá também aquelas que permanecerão "presas" na catação por conta de dívidas contraídas com seu empregador ${ }^{6}$. Uma característica comum é que estes(as) trabalhadores(as) usualmente se encontram à margem do sistema de proteção do Estado, recebendo pouco ou nenhum tipo de assistência em relação a saúde, moradia etc.

Existe uma divisão na forma como os(as) trabalhadores(as) se inserem na atividade de catação. Alguns estão produzindo em cooperativas, de maneira organizada e partilhada, e outros exercem esse trabalho como meio de sobrevivência, buscando suprir as dificuldades do cotidiano e trabalhando de forma mais individualizada, precária e desassistida. Em outras palavras, é como se de um lado tivéssemos a catação como recurso limite de sobrevivência e, de outro, tivéssemos tal atividade como possibilidade de sustento e de organização coletiva de famílias de catadores.

Ressaltamos que não se trata de colocar a catadora e o catador como excluídos ou vítimas da sociedade. Contudo, talvez possamos considerá-los como estando "nem dentro nem fora, mas nas margens", seguindo a perspectiva de Robert Castel (2011) ${ }^{7}$. Isto é, as(os) catadoras(es) não estão fora da sociedade - vide a ocupação espacial da cidade como um todo, realizada por estes trabalhadores -, no entanto, é possível dizer que eles não ocupam um lugar reconhecido no mercado formal, e muitos parecem pouco suscetíveis de se inserir em postos de trabalho formais (Castel, 2011). Entendemos que as(os) catadoras(es) são sujeitos importantes no contexto da cadeia produtiva de materiais recicláveis e que, embora marginalizadas(os) e pouco reconhecidos socialmente, têm conseguido avanços significativos através da luta pela efetivação dos seus direitos enquanto trabalhadoras/es. Uma das reivindicações do movimento dos/as catadores/as é estabelecer acordos e parcerias com os governos municipais para a realização da coleta seletiva de lixo.

Conforme Gonçalves (2004), a atividade de coleta seletiva é realizada há várias décadas no Brasil por meio do trabalho informal feito por catadoras(es). A autora afirma que as(os) catadoras(es) sempre estiveram presentes com mais ou menos intensidade no processo de gerenciamento dos resíduos. A coleta seletiva, enquanto processo que visava a separar os materiais passíveis de serem reutilizados, desenvolveu-se significativamente em vários países, sendo os Estados Unidos, aparentemente, o pioneiro, ainda no início do século XX (Calderoni, 2003). A primeira experiência de coleta seletiva no Brasil foi implantada em 1985, em um bairro de Niterói (Calderoni, 2003).

Atualmente, a responsabilidade pela coleta seletiva é dos municípios. No cenário atual de disputa pelo mercado de resíduos, tem-se basicamente de um lado as(os) catadoras(es) utilizando-se da coleta manual e, de outro, as empreiteiras, contratadas pelas prefeituras, com a coleta mecanizada. Essa disputa entre catadores e empreiteiras torna-se mais aguda em cidades onde existem grupos de catadores organizados em cooperativas ou associações. Na medida em que esses grupos se organizam, eles podem cobrar dos órgãos públicos a implantação da coleta seletiva feita exclusivamente por catadores (previsto na Lei $\mathrm{n}^{\mathrm{o}}$ 11.445-7), como já ocorre em algumas cidades.

\footnotetext{
6 Neste caso, estamos nos referindo aos chamados "donos de ferro-velho", muitos dos quais, como ouvimos em relatos de catadoras(es), possuem pequenos comércios "frios" de gêneros alimentícios e de higiene, que são trocados pelos materiais recicláveis que os catadores coletam. O problema é que nem sempre as(os) catadoras(es) têm controle sobre seus gastos (a "caderneta" fica com o patrão) e sobre sua produção (o empregador "rouba na balança").

$7 \mathrm{O}$ autor descreve a margem como o espaço social destinado às vítimas da precarização do trabalho, àqueles que são classificados como supranumerários, ou seja, que não encontram mais possibilidades de inserção no mercado de trabalho formal.
} 
Um dos entraves que as(os) catadoras(es) enfrentam em seu processo de organização é a dependência dos atravessadores de mercado (donos de ferro-velho e outros). São pessoas que, ao avesso dos "empreendimentos solidários", montam pequenas ou médias empresas, em sua maioria clandestinas, e compram os materiais coletados pelas(os) catadoras(es), pagando o que lhes for conveniente e, muitas vezes, "roubando na balança".

As relações estabelecidas com os atravessadores são viciosas. Uma estratégia bastante comum utilizada pelos atravessadores é o pagamento à vista para as(os) catadoras(es) da carga entregue no dia. Assim que a carga é entregue e pesada, é efetuado o pagamento da mesma. Cria-se com isso uma espécie de ilusão de que sempre se terá dinheiro, quando o contrário é o que acontece, pois se elimina a possibilidade de um planejamento a curto ou médio prazo para administrar o uso dos recursos financeiros. Dessa forma, as necessidades das(os) catadoras(es), que já eram pautadas pelo imediatismo, são reforçadas.

Apesar dos avanços conseguidos, como o reconhecimento das(os) catadoras(es) como categoria profissional pela $\mathrm{CBO}^{9}$, os desafios da categoria ainda são muitos. De acordo com Telles (1994):

As atividades no mercado informal, por mais constantes e persistentes que venham a se tornar, não são consideradas trabalho, sendo este a rigor definido por referência à carteira de trabalho assinada que lhes [aos trabalhadores] confere identidade e lhes garante direitos sociais, tudo o mais caindo na categoria genérica das atividades de sobrevivência, algo como "viração", que, a rigor, caracteriza o pobre, mas não o trabalhador (p. 99).

Ainda nesse contexto, Gonçalves (2004) afirma que as(os) catadoras(es) de materiais recicláveis podem ser vistos como exemplos de atores de longa data no cenário brasileiro. Se antigamente catar lixo era uma atividade realizada apenas pela mendicância, com o intuito de conseguir alimentos e roupas para o uso pessoal, hoje o catador de material reciclável é parte integrante da cadeia da reciclagem no país.

A atividade de catação, como descrevem Dias e Matos (2008), apesar das dificuldades, tem passado por um processo gradual e contestado de reconhecimento do papel histórico das(os) catadoras(es) como "agentes socioambientais". Um exemplo dessa mudança é a construção de programas nacionais, estaduais e municipais de apoio ao trabalho dos catadores, como a criação do Fórum Lixo e Cidadania, em 1998, apoiado pela UNICEF. Este fórum buscava a erradicação do trabalho de crianças nos lixões, assim como a gradual extinção dos lixões a céu aberto e melhores condições de trabalho para os catadores (Dias \& Matos, 2008).

Nessa direção, foi criado, em 2003, o Comitê Interministerial de Inclusão Social de Catadores de Materiais Recicláveis, a partir da pressão exercida por entidades como o MNCR. O comitê trabalha juntamente com outros dez órgãos federais na elaboração de ações voltadas para a área de gerenciamento de resíduos: "Nos últimos dez anos, recursos de diversos programas federais passaram a ser alocados no setor de resíduos sólidos, em especial em programas específicos de capacitação de catadores" (Dias \& Matos, 2008, p. 254).

Devemos considerar também que é recente a visibilidade que o tema vem tendo na sociedade e, "embora tenha crescido o número de trabalhos acadêmicos sobre catadores organizados em cooperativas e associações, a questão das relações de gênero é pouco explorada analiticamente" (Crivellari, Dias \& Pena, 2008, p. 311).

\footnotetext{
8 Termo utilizado pelos catadores para designar um dos artifícios que o atravessador utiliza visando ludibriá-los. Aproveitando-se muitas vezes de aspectos como o baixo grau de escolaridade de alguns catadores, os atravessadores modificam a regulagem da balança, colocando sempre para pesar menos que o real.

9 Classificação Brasileira de Ocupações, descreve as(os) catadoras(es) como "os trabalhadores da coleta e seleção de material reciclável [que] são responsáveis por coletar material reciclável e reaproveitável, vender material coletado, selecionar material coletado, preparar o material para expedição, realizar manutenção do ambiente e equipamentos de trabalho, divulgar o trabalho de reciclagem, administrar o trabalho e trabalhar com segurança" (ver www.mtecbo.gov.br/cbosite).
} 
Buscando analisar as conexões entre as relações de gênero e de trabalho, a seguir descreveremos, primeiramente, como se constituíam as oficinas de formação para catadoras(es) no universo estudado e de que maneira as questões de gênero atravessavam os momentos de formação. Em seguida, trataremos de como situações ligadas ao trabalho dos catadores nas ruas e no galpão de reciclagem alteram, em situações específicas, as tradicionais atribuições masculinas e femininas.

\section{Nos espaços de formação}

A inserção em campo incluiu ocupar um lugar de apoio em uma equipe formada por integrantes do MNCR, universitários e pessoas ligadas à comunidade local. A função da equipe era elaborar e desenvolver as "formações" para catadores(as). Tais atividades consistiam em oficinas que tratassem de temas relacionados ao universo de trabalho dos catadores, como o conhecimento da cadeia produtiva dos materiais recicláveis e o trabalho de catadores em cooperativas. Foram elaboradas seis oficinas com temas pré-estabelecidos ${ }^{10}$ e que obedeciam às diretrizes de um projeto ${ }^{11}$ do qual o MNCR era beneficiário. Ocorriam uma vez por semana, e cada encontro durava aproximadamente três horas.

As oficinas de formação possibilitaram que conhecêssemos melhor os habitantes do bairro Tom Jobim, localidade pobre e dotada de pouca infraestrutura urbana. Nesse local, mantivemos contato regular com várias(os) catadoras(es) que ali residiam, permitindo que observássemos seu cotidiano a partir de outro ângulo, não apenas no contexto de trabalho. Levantar cedo e preparar-se para um dia de trabalho nas ruas ou no galpão era diferente de preparar-se para participar de uma manhã de curso.

As oficinas do bairro Tom Jobim eram oferecidas no salão de uma creche, cedido pelas diretoras do local. Procuramos seguir um horário que se adequasse à rotina da maioria dos integrantes da oficina. A manhã (das $8 \mathrm{~h} 30 \mathrm{~min}$ às $11 \mathrm{~h} 30 \mathrm{~min}$ ) foi considerado adequada, pois as mulheres (maioria no curso) faziam a catação na parte da tarde. O turno da manhã era utilizado por elas (e não seus maridos/companheiros) para cuidarem da higiene das crianças, alimentá-las e encaminhá-las à escola ou à creche. A saída do curso às 11 h30min também foi programada para que algumas catadoras buscassem os filhos na escola ou creche.

Ao final de cada oficina, um pequeno grupo, composto exclusivamente por catadoras, aproximadamente de quatro a cinco, costumava permanecer no salão. Nesses momentos, falavam sobre assuntos ligados ao seu cotidiano, como suas angústias e dissabores em relação aos maridos e filhos e as lutas diárias em busca da sobrevivência. Por vezes, ouvíamos sobre a relação conflituosa com os chamados "ferros-velhos" ou com a cooperativa de reciclagem da qual algumas faziam parte. Essas conversas também constituíram uma forma de aproximação mais informal entre as catadoras e quem oferecia as oficinas.

Eliete (24 anos) e Lúcia (26 anos), por exemplo, duas irmãs que participavam das formações, sentavam-se sempre uma ao lado da outra. Fora do ambiente das oficinas, era comum encontrarmos as duas com suas amigas na rua - quando não estavam catando -, andando para cima e para baixo, parando em algumas esquinas que ofereciam uma visão maior do bairro, procurando inteirar-se das novidades ou até mesmo deslocando-se "só pelo prazer dos encontros" (Fonseca, 2004, p. 24) ${ }^{12}$.

10 Os principais temas abordados foram: direitos sociais e participação nos conselhos municipais de políticas públicas; consolidação de um centro de referência em coleta seletiva e formação de multiplicadores para atuarem nas oficinas de formação.

11 Fortalecimento do associativismo e do cooperativismo dos catadores de materiais recicláveis: formação para a autogestão. Assistência técnica e mobilização no estado do Rio Grande do Sul - Cataforte.

12 Este trabalho apresenta uma discussão sobre a sociabilidade em grupos populares na periferia de Porto Alegre. 
No decorrer das oficinas de formação, as duas irmãs destacavam-se por citar fatos de cunho pessoal, às vezes dramáticos, às vezes engraçados. Lúcia contou-nos que recentemente sofrera com uma traição do marido. Quando descobriu, os dois acabaram brigando e trocando insultos. Declarou que teve "depressão" por causa disso e que procurou ajuda de uma psicóloga no Centro de Referência de Assistência Social em seu bairro. Conforme Lúcia, o tratamento com a psicóloga não deu certo, pois era "terapia de grupo", e ela não se sentia à vontade para falar de si na frente de "um monte de desconhecidos". "Eu começava a ver o meu problema no dos outros e, também, tudo que eu ouvia dos outros, eu pegava pra mim. Aí, invés de resolver os meus problemas, eu saía com mais ainda, com os problemas dos outros."

Duarte (1988), em seu estudo sobre as classes trabalhadoras urbanas, faz uma analogia do lugar da mulher como sendo aquele da ordem privada/doméstica, e o do homem, o espaço público. A "troca" constante desses "lugares" acarretaria em certo conflito para o sujeito. Segundo o autor,

a correlação com o público que a "crise de nervos" feminina dramatiza como efeito encontra-se como causa na frequente perturbação nervosa de que é acometida a mulher que trabalha. Pois eis que neste caso o seu corpo de qualidades estruturais se vê ameaçado por uma condição anômala e incompatível: porque pública, porque externa, porque "antimoral"... No homem a prevalência de força supõe que esteja encoberta a sensibilidade nervosa (p. 181).

Nas discussões realizadas durante e depois das oficinas, conversávamos, entre outros assuntos, sobre relações de gênero e sexualidade. Muitas vezes, tais temas carregavam histórias cheias de decepções, esperanças e, até, de humor. Em um dos encontros, Lúcia falou novamente sobre a frustração amorosa que tivera recentemente. Fora traída pelo marido, pai de sua filha de 3 anos. Naquele momento, Lúcia estava "dando um tempo" para os relacionamentos, não queria que se repetisse a mesma situação. "Não quero mais saber de homem", dizia, fazendo em seguida a seguinte colocação: "A gente é preparada pra acreditar que vai crescer e vai ter um príncipe encantado. Só que esse príncipe nunca chega, é ilusão”.

Alguns dias depois, ao ser provocada por uma amiga sobre o fato de ainda estar solteira, Lúcia respondeu: "O que vou fazer se quem eu quero não me quer?". Percebemos que a instabilidade e a precariedade presentes nas relações de trabalho de alguns catadoras(es), muitas vezes, eram acompanhadas de instabilidade relacional, e isso emergia nas oficinas, na forma das narrativas sobre as relações afetivas com os homens.

Eliete, a irmã de Lúcia, era mãe de um menino de 2 anos e duas meninas, com 3 e 8 anos. A mais velha era "adotada". Segundo Eliete, "a mãe deixou ela um dia aqui em casa e depois nunca mais voltou, aí ela foi ficando aî". Em determinada ocasião, ao fim de uma oficina, Eliete, a mais espontânea do grupo, falou de forma bem humorada da situação que estava vivenciando com seu companheiro, que trabalhava como peão em uma propriedade rural. "Ele fica às vezes mais de quinze dias sem aparecer em casa!", disse, o que causou certo alvoroço entre as outras catadoras do grupo, pela conotação sexual que, de fato, Eliete quisera dar a sua declaração. Aproveitando-se do momento de descontração, a mesma afirmou: "Quando ele tá aí, aí tem que comparecer todos os dias!". Neste caso, encontramos uma forma de relato no qual "o tom da 'performance' não [era] de desabafo, mas sim de divertimento" (Fonseca, 2004, p. 113). A fala da catadora também nos leva a pensar que o espaço das formações era aquele em que as mulheres traziam aspectos dos relacionamentos com os homens, o que colocava em evidência questões referentes à maneira como se constituíam as masculinidades naquele contexto.

Percebemos que no âmbito doméstico as catadoras reproduziam o discurso masculino de que a "masculinidade se prova por um corpo ativo" (Jardim, 2001, p. 195). A demanda por esse corpo ativo do homem é encontrada na fala de Eliete, quando diz que o marido "tem que comparecer", referindo-se à postura que espera que o marido adote na esfera das relações conjugais. 
É interessante observar, conforme Fonseca (2004, p. 127), que nas narrativas das mulheres "os homens agem, ameaçam, mas raramente assumem o papel de interlocutor que escuta e opina. As personagens que dão suporte à história são, na maioria, mulheres, assim como as ouvintes da narradora". Cabe ressaltar ainda que, nas relações de trabalho do galpão de reciclagem, a "posição ativa" era muito mais das mulheres do que dos homens, o que de certo modo tensionava o código masculino nas relações de trabalho.

\section{No trabalho}

Jane trabalhava havia mais de cinco anos em uma unidade de triagem (também chamada de galpão de reciclagem), situada em localidade distante do perímetro urbano da cidade. Foi o primeiro emprego da catadora. No momento da pesquisa, tinha 32 anos, estava separada e tinha seis filhos (sendo três com idade de até 7 anos), com os quais morava em uma casa de quatro cômodos em um bairro próximo ao galpão de reciclagem. A moradia de Jane tinha água encanada, mas o esgoto era despejado a céu aberto. Possuía instalação da energia elétrica regular. Sua renda aproximada oriunda da catação era de 450 reais. Estudou até a terceira série e não tinha interesse em voltar para a sala de aula. Jane se definia como uma pessoa bastante ativa no trabalho, e exercia função de protagonista nas atividades que realizava. Nos dias de carregamento dos caminhões para posterior venda do material reciclável do galpão, "era tudo no muque" - dizia a catadora. Apesar de haver um carrinho para carregar os fardos e um elevador que subia os mesmos até a carroceria do caminhão, as catadoras não se limitavam a usar esses dois equipamentos. Com o intuito de apressar o carregamento (em princípio, quanto mais rápido fosse feita a venda, mais cedo elas(es) receberiam), empurravam manualmente os fardos até o elevador, os quais pesavam entre cem e duzentos quilos, dependendo do material.

Era necessário que duas ou três pessoas subissem no caminhão para receber os fardos. Por vezes, a subida dos fardos do chão até a carroceria tornava-se um trabalho arriscado para as catadoras, sobretudo quando continham latas de óleo e de sobras de ferro em geral. Mesmo com o uso de luvas, invariavelmente entrava-se em contato com alguma aresta ou ponta cortante que sobressaía do fardo, o que ocasionava corriqueiramente pequenos cortes nas mãos. Nem sempre as catadoras que ficavam em cima do caminhão para receber a carga conseguiam êxito. Jane contava que, às vezes, o fardo estava mal amarrado e ficava "molengo", e isso dificultava o trabalho de quem estava em cima do caminhão. "Tinha que prestar atenção para não se desequilibrar e cair de cima do caminhão e, ao mesmo tempo, tinha que cuidar para o fardo não cair em cima das gurias".

Segundo Jane, dificilmente saía-se do carregamento sem algum tipo de marca no corpo. Era corriqueiro vê-las com arranhões, hematomas, "bolas" nos braços e dedos, de tanto "levantar peso". A catadora falou-me de uma ocasião em que chovia no bairro, estavam com poucos trabalhadores no galpão e tiveram de "chamar um homem" da vizinhança para ajudar no carregamento. "O cara trabalhou até a metade da carga e foi embora! Não aguentou o tranco! Ele ficou brabo e disse: 'Não sei como essas mulheres aguentam, isso não é trabalho pra gente! Eu estou caindo fora!". Jane disse que tiveram de continuar o carregamento mesmo com chuva, pois, caso contrário, poderiam deixar de receber o pagamento.

Ao ser indagada sobre o motivo de existirem muito mais mulheres do que homens trabalhando na unidade de triagem e na atividade de catação ${ }^{13}$, Jane afirmou não saber ao certo a resposta, mas acredita que: "Não tem homem que aguente trabalhar aqui. É um serviço muito

13 Em pesquisa realizada no final dos anos 1990, Nardi (2006) aponta que havia maior número de mulheres nos grupos de trabalhadores informais entrevistados. Este fato estaria relacionado a uma maior proporção de mulheres demitidas e com dificuldade de retornar ao mercado formal de trabalho, como indicavam as estatísticas de desemprego da época. 
pesado!". É uma opinião diferente da emitida por outra catadora, que qualificava o trabalho de prensagem executado pelos homens como o mais difícil. Jane também abandonou o trabalho no galpão, pois - após ter ficado um longo período - sentia muita dor nos punhos, e isso estava impossibilitando sua permanência na unidade de triagem. "Não dá mais. Chegou um ponto que eu não aguento mais ficar lá", disse, mostrando os braços inchados devido ao trabalho repetitivo e pesado.

Outro aspecto tenso da relação gênero/trabalho no contexto estudado emerge na participação das mulheres na direção do movimento. A responsável pela coordenação da equipe de trabalho do galpão era uma catadora, a qual tinha forte papel de liderança entre suas(seus) colegas. Percebemos que tal liderança era mais reconhecida no local de trabalho das(os) catadoras(es) do que nos espaços de participação e discussão do MNCR. Nos momentos de discussão política do MNCR, eram as discussões dos "homens do Movimento" que direcionavam as tomadas de decisão a partir do que era debatido. A presença feminina no contexto referido se evidenciava mais em termos numéricos do que nos rumos e discussões relacionados à política do MNCR. Nesse caso, observávamos nas instâncias do Movimento que a mulher continuava "administrando a casa" (galpão), enquanto os homens praticamente tomavam conta das atividades relacionadas ao "público" (fora do galpão) ${ }^{14}$.

Outra situação exemplar da tensão entre trabalhos de homens e mulheres neste contexto é o de uma catadora que utilizava como ferramenta de trabalho um "carrinho elétrico" que estava em processo de testes e poderia ser uma alternativa para a realização de trabalho com menos esforço físico. A catadora testava e relatava para um integrante do MNCR todos os defeitos que o carrinho apresentava. Os dados a respeito do carrinho eram, então, repassados para o fabricante, que tomaria as medidas necessárias para corrigir os defeitos. Dentre os problemas encontrados, a catadora relatou uma situação na qual o carrinho estava com problema no dispositivo de frenagem. Os freios ficavam nas duas rodas dianteiras, e logo foi verificado que seu posicionamento prejudicava a dirigibilidade. A catadora narrou um episódio em que quase quebrou um braço ao tentar fazer uma curva em meio a uma via movimentada. Na ocasião, o carrinho precisou ser freado e acabou parando de maneira brusca, fazendo que a alavanca de direção lhe atingisse, colocando em risco a vida da catadora. Este exemplo nos mostrou que essa nova tecnologia na área da catação, mesmo que estivesse em fase de testes, não foi concebida com a segurança necessária para seu(sua) condutor(a). Percebemos também que a palavra final sobre o que deveria ser modificado no carrinho não era de quem estava experimentando "na pele e no corpo" as dificuldades de conduzir aquele novo equipamento, e, sim, do integrante do Movimento que fazia a manutenção dos carrinhos.

Por meio de conversas com catadores do galpão de reciclagem, verificamos ainda que em alguns momentos eles se sentiam intimidados pela "postura" das mulheres que trabalhavam no local. Ao longo das observações, percebemos que essa intimidação não ocorria somente pelo fato de os homens estarem em minoria na unidade de triagem, mas também se relacionava a determinadas estratégias produzidas pelas mulheres de testar se os homens que fossem trabalhar naquele local conseguiriam realizar as mesmas atividades que elas, e com o mesmo desempenho. A esse respeito, um catador relatou que as mulheres do galpão gabavam-se de fazer todo o trabalho pesado do local, dizendo que os homens que eventualmente iam trabalhar no galpão "não conseguiam ficar muito tempo no serviço".

Observamos que, no galpão de reciclagem, as mulheres executavam o trabalho "pesado" e, com isso, detinham o status por elas denominado de quem "aguentava o tranco". Os homens que trabalhavam na catação eram considerados por elas como aqueles que não suportam o trabalho pesado do dia a dia. Paradoxalmente, alguns trabalhos que também exigiam bastante esforço físico - como a prensagem dos materiais recicláveis - eram delegados

14 Neste caso, evidencia-se de forma mais clara o que Hirata (2009) chama de divisão sexual do trabalho, a qual se afirma na posição de que há trabalhos de homens e trabalhos de mulheres. Nosso argumento é que tal distribuição de tarefas é menos estanque na medida em que aumenta a precariedade do trabalho no coletivo de catadores(as). 
aos homens pela razão de serem "muito pesados", portanto "coisa pra homem". Em outros momentos, vimos que o dispêndio de forças utilizado no trabalho realizado nos galpões, na visão de um homem, "não é coisa de gente" (Ribeiro, 2011).

Podemos afirmar que emergia nas práticas das(os) trabalhadoras(es) uma contestação da naturalização das funções e atributos tradicionais do homem e da mulher no trabalho e das relações de poder entre homens e mulheres estabelecidas naquele contexto. Neste caso, relações de gênero e de trabalho configuravam e "determinavam" modos de viver e trabalhar em um contexto marcado pela precariedade em um sentido amplo. Isso indica que os processos de subjetivação que atravessam a vida das(os) catadoras(es) no campo das relações de gênero e de trabalho, quando colocados frente à questão da precariedade, são marcados pela instabilidade dos tradicionais papéis masculinos e femininos, questionando, de certo modo, a divisão sexual do trabalho. Paradoxalmente, o fato de as mulheres serem a maioria entre a população de catadores não garante melhores condições de trabalho, pois exercem ocupação quase totalmente desprovida do acesso e da efetivação dos direitos sociais.

\section{Considerações finais}

Escrever sobre catadoras(es) de materiais recicláveis remete para um contexto marcado pela heterogeneidade das relações no que tange à diversidade de práticas exercidas. Contudo, percebemos que há uma característica comum do trabalho realizado por mulheres nos galpões de reciclagem: em um contexto de precariedade, as mulheres ocupam a margem mais precária e mais desgastante na cadeia produtiva da catação/reciclagem. Neste artigo, o objetivo foi, portanto, analisar como a precariedade do trabalho das(os) catadoras(es) inflexiona as relações de gênero no trabalho.

Partimos do princípio de que a precarização do trabalho está ligada à ausência de suportes sociais garantidos pelo Estado, ou seja, pela insuficiência da extensão da propriedade social (Castel, 1998). A propriedade social se distingue da propriedade coletiva e da propriedade privada, pois é aquela que fornece os suportes sociais para o indivíduo, como, por exemplo, a previdência social, o fundo de garantia e o seguro-desemprego. A atividade de catação acaba sendo, para a maioria das(os) catadoras(es), o último recurso, o qual se situaria em uma margem limítrofe entre a venda da força de trabalho (contratual) e atividades como mendicância ou atos ilícitos. Isso ocorre de maneira mais evidente quando as(os) catadoras(es) não conseguem se filiar a redes como o serviço público, os empreendimentos de economia solidária e movimentos sociais. Ser catador permite, mesmo que fragilmente, estar protegido pela "marca simbólica do trabalho, [a qual] funciona como proteção moral contra a ilegalidade (o roubo, a prostituição, o tráfico), a bebida, o devaneio e o 'pensar bobagem' (a loucura) que ronda as comunidades pobres das grandes cidades" (Nardi, 2006, p. 89). Acreditamos que mudanças como a implantação de uma coleta gerida por catadores(as), criação de espaços de formação e o reconhecimento (efetivo) da categoria como profissão podem contribuir para que essas(es) trabalhadoras(es) construam formas menos precárias de se relacionar com o trabalho. Seria importante também a criação de políticas que visem à eliminação da dependência dos catadores em relação aos atravessadores de mercado e que busquem alternativas mais justas de negociação.

Ao longo do artigo, buscamos enfatizar a ligação existente entre a precariedade do trabalho das(os) catadoras(es) e as questões de gênero presentes no campo pesquisado. Como vimos, as mulheres são a maioria no trabalho de catação (em especial nos galpões) e, ao mesmo tempo, são elas que mais acessam os serviços públicos de saúde e de assistência, sendo o público-alvo da maioria das políticas sociais voltadas para famílias em situação de 
vulnerabilidade social. Assim, podemos considerar que estão minimamente assistidas pelo Estado, não nos aspectos de proteção associada à legislação trabalhista, mas naqueles referentes a assistência social e saúde. Acreditamos, então, que um dos fatores que tornam precário o cotidiano da mulher catadora é a série de atribuições e responsabilizações que lhe são colocadas tanto no espaço público quanto na esfera doméstica. Tais atribuições sobrecarregam a mulher/mãe/catadora. É possível afirmar que, quando as mulheres se percebiam como mais fortes que os homens, elas estavam se referindo não apenas à questão de força física, mas também à ideia de perseverança e responsabilidade, expressa no cuidado com os filhos, com a casa e consigo mesmas. Pensamos, contudo, que existe uma tensão presente nesta injunção paradoxal. Ao mesmo tempo em que se afirmam a força e a capacidade das mulheres, essas múltiplas atribuições contribuem para a precarização do trabalho das catadoras, pois limitam o tempo de formação e de dedicação ao envolvimento com o movimento organizado.

\section{Referências}

Beaud, S. \& Weber, F. (2007). Guia para a pesquisa de campo: produzir e analisar dados etnográficos (S. J. de Almeida $\&$ H. C. Nardi, Trad.). Petrópolis: Vozes.

Butler, J. (2008). Problemas de gênero: feminismo e subversão da identidade (2 $2^{\mathrm{a}}$ ed.). (R. Aguiar, Trad.). Rio de Janeiro: Civilização Brasileira.

Calderoni, S. (2003). Reciclagem no mundo e no Brasil. In P. Gonçalves (Org.), A reciclagem integradora dos aspectos ambientais, sociais e econômicos (pp. 27-31). Rio de Janeiro: DP\&A/Fase.

Castel, R. (2011). A discriminação negativa: cidadãos ou autóctones (F. Morás, Trad.) (2aㅡ ed.). Petrópolis: Vozes.

Castel, R. (1998). As metamorfoses da questão social: uma crônica do salário. Petrópolis: Vozes.

Crivellari, H. M. T., Dias, S. M. \& Pena, A. S. (2008). Informação e trabalho: uma leitura sobre os catadores de material reciclável a partir das bases públicas de dados. In H. M. T. Crivellari \& V. H. Kemp (Orgs.), Catadores na cena urbana: construção de políticas socioambientais (pp. 299-324). Belo Horizonte: Autêntica.

Dias, S. M. \& Matos, M. (2008). Fórum Lixo e Cidadania: inovação institucional na formulação de políticas públicas de resíduos sólidos. In H. M. T. Crivellari \& V. H. Kemp (Orgs.), Catadores na cena urbana: construção de políticas socioambientais (pp. 249-264). Belo Horizonte: Autêntica.

Do Carmo, M. S. F. (2008). A problematização do lixo e dos catadores: estudo de caso múltiplo sobre políticas públicas sob uma perspectiva foucaultiana. Tese de doutorado, Escola Brasileira de Administração Pública e de Empresas, Fundação Getulio Vargas, Rio de Janeiro.

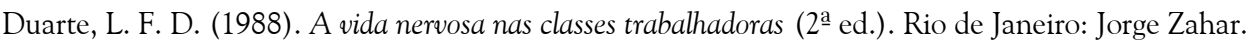

Fonseca, C. (2004). Família, fofoca e honra. Porto Alegre: Editora da UFRGS.

Foucault, M. (1988). História da sexualidade I: a vontade de saber (M. T. C. Albuquerque \& J. A. Guilhon Albuquerque, Trad.) (19a ed.). Rio de Janeiro: Graal.

Freitas, M. V. A. \& Neves, M. A. (2008). Cidade e trabalho: as experiências dos catadores de papel em Belo Horizonte. In H. M. T. Crivellari \& V. H. Kemp (Orgs.), Catadores na cena urbana: construção de políticas socioambientais (pp. 83-108). Belo Horizonte: Autêntica.

Gonçalves, R. S. (2004). Catadores de materiais recicláveis: trajetória de vida, trabalho e saúde. Dissertação de Mestrado, Escola Nacional de Saúde Pública Sérgio Arouca, Fundação Oswaldo Cruz, Rio de Janeiro.

Hirata, H. A. (2009). A precarização e a divisão internacional e sexual do trabalho. Sociologias, 11, 24-41.

Jardim, D. F. (2001). Performances, reprodução e produção dos corpos masculinos. In O. Leal (Org.), Corpo e significado: ensaios de antropologia social (pp. 193-205). Porto Alegre: Editora da UFRGS.

Meyer, D. S. (2008). Gênero e educação: teoria e política. In G. L. Louro, J. Felipe \& S. V. Goellner, Corpo, gênero e sexualidade: um debate contemporâneo na educação (4⿳亠丷厂 ed.) (pp. 9-27). Petrópolis: Vozes.

Nardi, H. C. (2006). Ética, trabalho e subjetividade: trajetórias de vidas no contexto das transformações do capitalismo contemporâneo. Porto Alegre: Editora da UFRGS.

Ribeiro, I. M. (2011). "Aguentando o tranco": etnografia com catadoras(es) de materiais recicláveis. Dissertação de Mestrado, Instituto de Psicologia, Universidade Federal do Rio Grande do Sul, Porto Alegre.

Schamber, P. J. (2006). Morfologia del fenómeno cartonero em Buenos Aires. In G. Wilde \& P. J. Schamber (Orgs.), Culturas, comunidades y processos urbanos contemporâneos (pp. 14-41). Buenos Aires: SB. 
Telles, V. (1994). Pobreza e cidadania. In H. S. Martins \& J. R Ramalho (Orgs.), Terceirização, diversidade e negociação no mundo do trabalho (pp. 24-43). São Paulo: HUCITEC/CEDI/NETS.

\section{Endereço para correspondência}

izaqueribeiro@yahoo.com.br, hcnardi@gmail.com,machadops@gmail.com

Recebido em: 08/12/2011

Revisado em: 07/09/2012

Aprovado em: 11/09/2012 